\title{
O ENSINO DA ENGENHARIA SOB A ÓTICA DE ALUNOS E PROFESSORES: ESTUDO DE CASO DA ENGENHARIA DE MINAS DA UNIVERSIDADE FEDERAL DE MINAS GERAIS
}

\author{
Lucas F.Porto-fportolucas@gmail.com \\ Andreia B.Henriques - abicalho@demin.ufmg.br \\ Universidade Federal de Minas Gerais, Faculdade de Engenharia de Minas \\ Avenida Antônio Carlos 6627 - Escola de Engenharia - Pampulha \\ 31270-010 - Belo Horizonte - Minas Gerais
}

Resumo: Este trabalho apresenta uma análise da perspectiva dos docentes e discentes da Escola de Engenharia de Minas da UFMG em relação ao curso e à instituição. Através de uma pesquisa exploratória foram quantificados e qualificados parâmetros relacionados à satisfação quanto a qualidade do ensino, infraestrutura da escola e conexão com o mercado. A análise e debate dos resultados permite inferir as principais insuficiências e qualidades do curso, além de próximos passos que podem levar a instituição a renovar seu processo de ensino e aprendizagem. As devidas projeções deste trabalho podem ser usadas para a otimização das metodologias de ensino das diversas Instituições de Ensino Superior.

Palavras-chave: Satisfação Acadêmica. Inovação. Metodologias de Ensino. Engenharia.

\section{INTRODUÇÃO}

As mudanças tecnológicas, sociais, culturais e ambientais das últimas décadas vêm forçando empresas a inovarem rápido para se manterem competitivas, bem vistas pela sociedade e atraindo grandes talentos (AUGUSTO et al. 2008). Augusto et al., aponta ainda que essas inovações tecnológicas trouxeram "impactos nas relações de trabalho de toda ordem".

Contudo, apesar dessas mesmas mudanças impactarem tão profundamente quanto as Instituições de Ensino, estas apresentaram baixíssima capacidade para se adaptar e inovar em seu trabalho. Segundo Anghnoni (2015), a experiência de ensino da população ocidental é exatamente a mesma há mais de 150 anos, fortemente inspirada no modelo gratuito e massificado que surgiu na Prússia no século XVIII, e valoriza linearidade, padronização, repetição e segmentação.

Este modelo funcionou até a Era Industrial, onde o trabalho era também repetitivo, previsível e linear (ANGHNONI, 2015). Nessa época vários cursos universitários surgiram para atender as demandas da indústria com sucesso.

Um deles é o curso de Engenharia de Minas da UFMG, criado no ano de 1966, que visa a formação de engenheiros com habilidades técnicas para atuar de forma criativa e crítica na resolução de problemas nas áreas de prospecção e exploração mineral, lavra de minas, beneficiamento mineral e fechamento de mina (BICALHO, 2017).

Este trabalho testa a hipótese de que o descompasso entre as rápidas mudanças das últimas décadas e a falta de adaptabilidade do ensino universitário gerou uma incapacidade, em alguns aspectos, do curso formativo em questão atender às necessidades tanto dos alunos, quanto dos professores, quanto da sociedade. 
Para Pinto et al. (2017), o atendimento ou a eliminação de uma necessidade está intimamente relacionada com a satisfação pelo serviço. Como notou Palacio et at. (2002), o nível de satisfação acadêmica é influenciado por diversos fatores dentre os quais podem se destacar: serviços pedagógicos, apoio que a instituição oferece e questões relacionadas às oportunidades no mercado de trabalho proporcionadas pela experiência no curso. A importância de medi-la no ambiente acadêmico, para Gomes et al. (2013), é que o nível de satisfação é um dos fatores fundamentais para a manutenção de alunos e está intimamente ligado ao sucesso e ao desenvolvimento da organização.

Este artigo retrata uma investigação cientifica, realizada na Faculdade de Engenharia de Minas da UFMG, tendo como objetivo identificar os principais fatores de (in)satisfação dos discentes e docentes em relação ao curso e propor mudanças implementáveis que promovam a renovação da escola e o seu alinhamento com as atuais demandas do mercado.

\section{METODOLOGIA}

Esta pesquisa consistiu em uma investigação qualitativa e quantitativa de caráter exploratório sobre as principais insatisfações e qualidades do curso, e também incluiu debates abertos aos 240 discentes matriculados, 13 docentes efetivos, 1 docente substitutivo e 6 docentes voluntários do curso, visando gerar soluções práticas para as tensões mais críticas mapeadas.

A investigação começou através de uma série de entrevistas contextuais, conceito do Design Thinking de Serviços que remete a uma técnica etnográfica de entrevistas realizadas no ambiente onde se dá o serviço, o processo ou o fenômeno estudado (STICKDORN e SCHNEIDER, 2010), realizadas com discentes, professores, ex-alunos, técnicos e empreendedores de engenharia de minas, buscando identificar os principais pontos de desenvolvimento do curso incluindo a perspectiva de todos impactados pelo serviço da faculdade.

Com os tópicos que tiveram maior relevância nas entrevistas foram produzidos dois Questionários de Satisfação: um focado nos alunos - Satisfação Acadêmica - e outro nos professores - Satisfação no Trabalho. Com o objetivo de avaliar quantitativamente quais desses tópicos eram os mais significativos para mudança formularam-se 26 (vinte e seis) perguntas para cada questionário, que foram respondidas de forma anônima por meio do Questionário Google, ferramenta gratuita disponibiliza online.

Para medir a satisfação e insatisfação dos discentes e docentes do curso, os entrevistados classificaram cada tópico da pesquisa de acordo com uma escala de 1 a 5 , sendo $1=$ Totalmente Insatisfeito e $5=$ Totalmente Satisfeito. Ambos os questionários foram divididos em três blocos. Uma síntese das perguntas do Questionário de Satisfação Acadêmica (para alunos) é apresentada no Quadro 1; e uma síntese do Questionário de Satisfação no Trabalho (para professores) no Quadro 2.

Ao final da pesquisa foram obtidas respostas de 19 docentes (95\%) e 151 discentes (63\%) com participação distribuída de forma homogênea entre os dez períodos do curso. Os dados coletados foram analisados utilizando-se estatística descritiva e inferencial.

Os 6 tópicos com notas mais baixas na pesquisa foram discutidos em duas reuniões abertas a todos os integrantes do departamento (DEMIN). Devido ao lockdown gerado pela pandemia, utilizou-se a plataforma online Zoom para os encontros. 


\section{Evento On-line}

Quadro 1 - Síntese do questionário direcionado aos estudantes

\begin{tabular}{|c|c|}
\hline ESTRUTURA/APOIO DA ESCOLA & Nível de Satisfação / Insatisfação \\
\hline $\begin{array}{c}\text { Infraestrutura dos Laboratórios } \\
\text { Ambientes de Estudo } \\
\text { Apoio Coordenação e Colegiado } \\
\text { Plataforma de Comunicação } \\
\text { (SIGA/MOODLE) } \\
\text { Divulgação Eventos Acadêmicos } \\
\text { Encaminhamento para Estágios } \\
\text { Profissionais } \\
\text { Atividades de Pesquisa e Extensão } \\
\text { Atividades de Empresa Júnior }\end{array}$ & $\begin{array}{c}5=\text { Totalmente Satisfeito } \\
4=\text { Parcialmente Satisfeito } \\
3=\text { Indiferente } \\
2=\text { Parcialmente Insatisfeito } \\
1=\text { Totalmente Insatisfeito }\end{array}$ \\
\hline COMPORTAMENTO DOCENTES & Nível de Satisfação / Insatisfação \\
\hline $\begin{array}{c}\text { Capacitação Técnica } \\
\text { Motivação } \\
\text { Compromisso com Ensino } \\
\text { Metodologia de Ensino } \\
\text { Didática } \\
\text { Formas de Avaliação }\end{array}$ & $\begin{array}{c}5=\text { Totalmente Satisfeito } \\
4=\text { Parcialmente Satisfeito } \\
3=\text { Indiferente } \\
2=\text { Parcialmente Insatisfeito } \\
1=\text { Totalmente Insatisfeito }\end{array}$ \\
\hline QUALIDADE DO ENSINO & Nível de Satisfação / Insatisfação \\
\hline $\begin{array}{c}\text { Grade Curricular } \\
\text { Carga Horária } \\
\text { Aplicabilidade Prática } \\
\text { Desenvolvimento de Habilidades } \\
\text { Relacionais } \\
\text { Nível de Colaboração com Colegas } \\
\text { Integração Escola - Empresas } \\
\text { Integração entre Períodos }\end{array}$ & $\begin{array}{c}5=\text { Totalmente Satisfeito } \\
4=\text { Parcialmente Satisfeito } \\
3=\text { Indiferente } \\
2=\text { Parcialmente Insatisfeito } \\
1=\text { Totalmente Insatisfeito }\end{array}$ \\
\hline
\end{tabular}




\section{Evento On-line}

Quadro 2 - Síntese do questionário direcionado aos educadores

\begin{tabular}{|c|c|}
\hline ESTRUTURA DE TRABALHO & Nível de Satisfação / Insatisfação \\
\hline $\begin{array}{c}\text { Relações com Instâncias de Poder } \\
\text { Supervisão sobre Trabalho } \\
\text { Apoio de Instâncias Superiores } \\
\text { Produtividade e União com Colegas } \\
\text { Departamento } \\
\text { Participação nas Decisões } \\
\text { Cumprimento de Normas e Acordos } \\
\text { Coletivos }\end{array}$ & $\begin{array}{c}5=\text { Totalmente Satisfeito } \\
4=\text { Parcialmente Satisfeito } \\
3=\text { Indiferente } \\
2=\text { Parcialmente Insatisfeito } \\
1=\text { Totalmente Insatisfeito }\end{array}$ \\
\hline BEM-ESTAR PROFISSIONAL & Nível de Satisfação / Insatisfação \\
\hline $\begin{array}{l}\text { Higiene, Salubridade e Espaço Físico } \\
\text { Objetivos e Metas } \\
\text { Trabalho enquanto Fato de Realização } \\
\text { Formas de Avaliação do Trabalho } \\
\text { Impacto do Trabalho sobre a Saúde } \\
\text { Autonomia para Tomar Decisões }\end{array}$ & $\begin{array}{c}5=\text { Totalmente Satisfeito } \\
4=\text { Parcialmente Satisfeito } \\
3=\text { Indiferente } \\
2=\text { Parcialmente Insatisfeito } \\
1=\text { Totalmente Insatisfeito }\end{array}$ \\
\hline QUALIDADE DO ENSINO & Nível de Satisfação / Insatisfação \\
\hline $\begin{array}{c}\text { Grade Curricular } \\
\text { Engajamento dos Alunos } \\
\text { Infraestrutura Disponível } \\
\text { Preparação com que Alunos Chegam } \\
\text { Nivel de Aprendizado que Alunos Saem } \\
\text { Dedicação e Responsabilização dos Alunos } \\
\text { Integração entre as Disciplinas } \\
\text { Atividades de Pesquisa e Extensão }\end{array}$ & $\begin{array}{c}5=\text { Totalmente Satisfeito } \\
4=\text { Parcialmente Satisfeito } \\
3=\text { Indiferente } \\
2=\text { Parcialmente Insatisfeito } \\
1=\text { Totalmente Insatisfeito }\end{array}$ \\
\hline
\end{tabular}

No primeiro dia, foram criados 5 grupos de 5 pessoas cada, em que cada grupo focou na discussão de apenas um tópico. Isto é, ao mesmo tempo, aconteceram 5 conversas paralelas sobre tópicos críticos (de maior insatisfação) da pesquisa: Metodologia de Ensino, Formas de Avaliação, Engajamento dos Alunos nas Aulas, Integração entre Períodos e Atividades de Empresa Júnior.

Utilizando a ferramenta World Café proposta por Brown e Isaacs (2007), que incita conversações significativas e estratégicas, os grupos se desfaziam e se misturavam, combinando percepções e ideias. Os insights de cada grupo foram registrados na ferramenta online e gratuita Jamboard, do Google.

No segundo dia, um grupo menor discutiu mais um tópico crítico identificado na pesquisa: Integração Escola-Empresas.

Em ambas as reuniões, o objetivo foi compreender qual necessidade não estava sendo atendida para se fazer presente a insatisfação, discutir mudanças almejadas, além de definir 
próximos passos concretos que levassem a Instituição para mais perto desse ideal. Os resultados dessa pesquisa serão expostos e explanados na seção a seguir.

\section{RESULTADOS E DISCUSSÃO}

\subsection{Pesquisa dos Discentes}

$\mathrm{Na}$ perspectiva dos discentes, a faculdade de engenharia de minas da UFMG possui ótima infraestrutura de laboratórios e ambientes de estudo. Aproximadamente $68 \%$ e $72 \%$ (respectivamente) dos alunos classificaram estes quesitos com notas 4 ou 5 , respondendo Parcialmente Satisfeito ou Totalmente Satisfeito no questionário. A alta nota para infraestrutura de laboratórios é positiva, pois é um fator fundamental na capacidade do curso de fornecer aos pesquisadores investigações de alto nível e para o desenvolvimento de conhecimento novo (NEGRI e SQUEFF, 2016).

Por outro lado, identificou-se na experiência dos discentes, 6 aspectos com grau de insatisfação significativo: Formas de Avaliação, Metodologia de Ensino e Didática, Integração com Empresas, Integração entre Períodos, Encaminhamento para Estágios Profissionais e Atividades de Empresa Júnior. Na Figura 1, observa-se que os quesitos Formas de Avaliação e Metodologias de Ensino apresentam mais de 50\% de insatisfação por parte dos estudantes, indicando temas essenciais para serem analisados.

Figura 1 - Principais temas de insatisfações dos discentes.

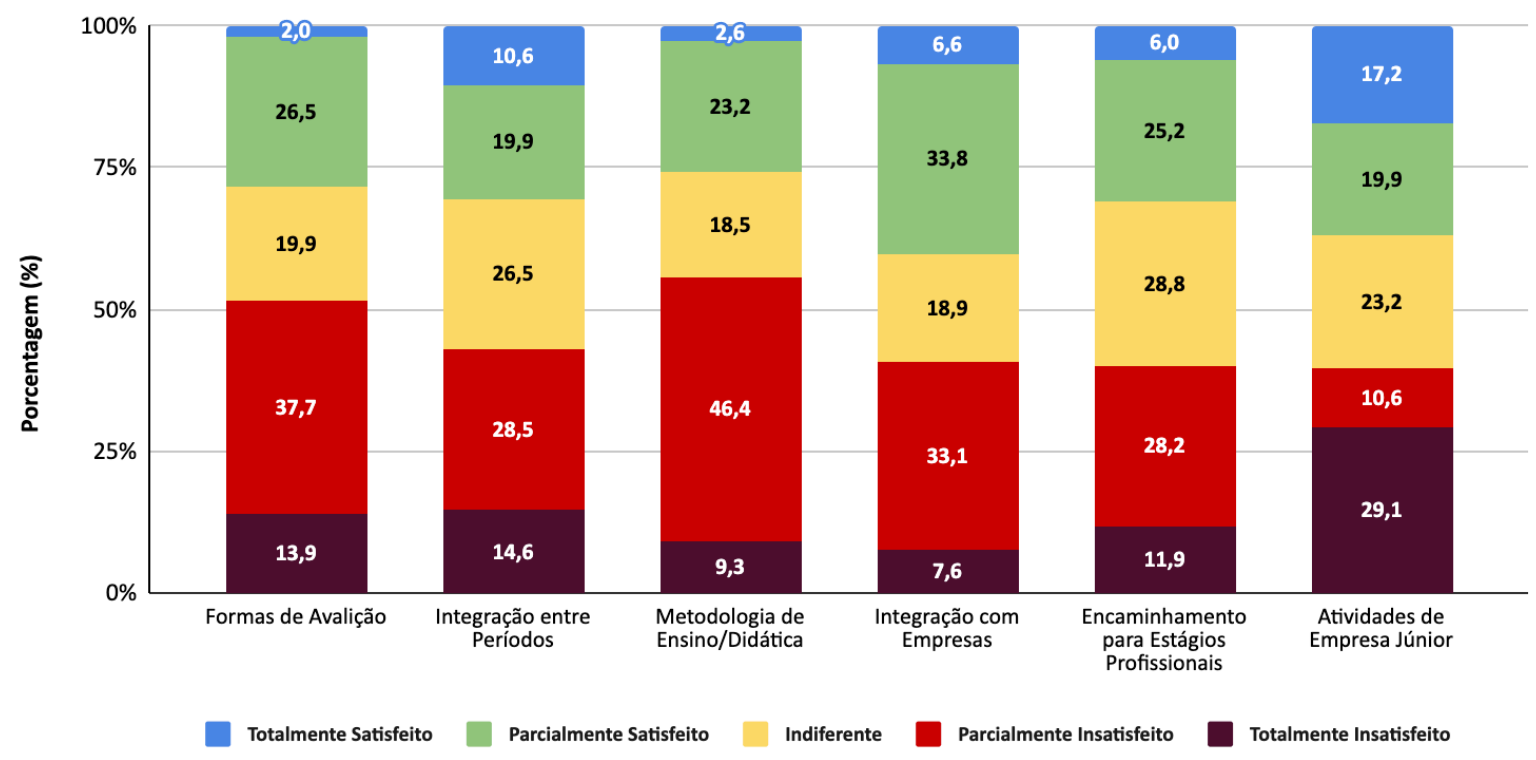

Fonte: Questionário de Satisfação dos discentes da engenharia de minas da UFMG (julho/2020)

Quanto às formas de avaliação, a insatisfação mais contundente é o desalinhamento do método de provas individuais que incentivam a memorização de curto prazo com as competências exigidas pelo mercado de trabalho atual. A pesquisa The Future of Skills da Pears, Oxford Martin School e Nesta (2017) levantou os principais conhecimentos e competências que serão demandados pelo mercado de trabalho até 2030, e aponta por exemplo: pensamento crítico, criatividade, aprendizagem ativa, resolução de problemas complexos, trabalho em equipe, negociação e tomada de decisões como algumas dessas habilidades. 
Entretanto, as avaliações tradicionais da engenharia são baseadas em provas que examinam justamente o contrário: a capacidade de memorizar grandes bateladas de informação e de absorver respostas prontas (VIDOTTO et al., 2005) - sendo que o computador já ultrapassou o ser humano há muitos anos nesse quesito. Outro ponto, é que as provas são geralmente exames individuais, porém, nenhum engenheiro trabalha sozinho. Como observa Sawyer (2007), nós estamos vivendo em uma "cultura de organização colaborativa...baseada em flexibilidade, conexão e conversação". As exigências do mercado atual são de conectar diferentes pontos de vista para se criar soluções sistêmicas e inovadoras para os desafios do nosso tempo.

Através dos debates abertos definiram-se dois comportamentos desejáveis para atualizar o modelo de avaliações: produzir atividades mais próximas às situações reais que o aluno irá vivenciar no mercado e substituir o modelo de 3 provas com pontuação 30/30/40, por avaliações mais fracionadas e mais diversificadas, contemplando a heterogeneidade da turma, desenvolvendo habilidades importantes para seu futuro e incentivando os alunos a se manterem em dia com a matéria. Dessa forma, atividades avaliativas em pequenos grupos, de 2 a 4 pessoas, que tragam para a sala situações que eles irão enfrentar no dia-a-dia de trabalho parecem estar alinhadas com as necessidades presentes do curso.

Seguindo para as metodologias de ensino e didática, notou-se que a grande insatisfação é decorrente da falta de renovação nos conteúdos, e na posição passiva que os discentes ocupam na aula. As aulas expositivas centradas no professor segundo Hazoff et al. (2008) podem resultar num retardamento da maturidade dos alunos, pois os coloca em total dependência dos professores e de currículos preestabelecidos. A conclusão dessa pesquisa é que as aulas expositivas não devem ser eliminadas, mas devem dar espaço para o aprendizado acontecer também pela troca entre alunos e pelo compartilhamento de conhecimentos do aluno para turma.

Esse equilíbrio parece derivar em relação ao semestre do estudante, nos primeiros períodos aulas expositivas são mais eficazes, quanto mais maduro e ao final do curso o aluno chega maior deve ser a participação deste na construção da própria aprendizagem.

Neste contexto, se faz necessário a visão de Sawyer (2007) de desmantelar o mito do "gênio solitário", que contém todas as respostas, para enxergar que as invenções mais revolucionárias da história e modernidade foram criadas pela "genialidade de grupo", que significa: criatividade impulsionada pela colaboração e inovação surgindo de uma "série de flashes" ou "clarões" de múltiplas mentes.

O que pode ser feito para que o aluno deixe de ser um agente passivo na sala de aula e se torne protagonista junto com o professor na transformação da experiência de ensinoaprendizagem? A resposta: diálogo. O trabalho do proeminente biólogo Humberto Maturana (p 48, 2008) afirma que "nossa existência humana é uma na qual podemos viver em qualquer mundo que gerarmos a partir de nossas conversações". A partir dessa perspectiva da evolução humana, a conversa entre as pessoas em sala de aula não é algo trivial, que deve ser rejeitada. A conversação aluno-professor e aluno-aluno é a força geradora de inteligência coletiva, fortalecimento de vínculos e descobrimento de novos conhecimentos.

Implementar uma cultura de diálogo significa olhar para os discentes não como objetos passivos e iguais, mas como sistemas vivos, repletos de recursos, vivências, conhecimentos e curiosidades, que devem participar ativamente da renovação constante do conteúdo e da experiência de ensino-aprendizagem.

Os alunos podem, por exemplo, ser atores importantes na Integração da Universidade com as Empresas - tópico com $41 \%$ de insatisfação. Muitos dos discentes da engenharia de minas da UFMG estagiam ou trabalham em empresas do setor privado, sendo possíveis pontes de conexão entre universidade e mercado. 


\section{Evento On-line}

O aspecto mais satisfatório do curso na perspectiva dos discentes é a Capacitação Técnica dos docentes, tendo $53 \%$ de respostas 4 e $21 \%$ de respostas 5 . Este resultado reforça a necessidade de se implantar metodologias de ensino mais eficazes, que permitam aos alunos usufruir da experiência e do conhecimento de seus orientadores.

\subsection{Pesquisa dos Docentes}

O Questionário de Satisfação no Trabalho indica que 32\% dos docentes lecionam engenharia de minas na UFMG há mais de 12 anos, 26\% dos docentes lecionam entre 3 e 12 anos e $42 \%$ dos docentes lecionam há menos de 3 anos.

Observa-se significativa satisfação em mais de $65 \%$ dos tópicos da pesquisa, nos quais a média das respostas foi maior do que 4,0. A satisfação em relação às Metas e Objetivos que o docente deve alcançar e à possibilidade do mesmo decidir com Autonomia sobre o Próprio Trabalho, receberam notas 4,21 $\pm 0,5$ e 4,63 $\pm 0,6$, respectivamente, e além disso, nenhuma das duas registrou qualquer insatisfação. Outro item muito bem avaliado foi a satisfação com o Trabalho como Fator de Realização, no qual todos os docentes se demonstraram satisfeitos $37 \%$ de notas 4 e $63 \%$ de notas 5 .

$\mathrm{Na}$ Figura 2, é apresentado um comparativo da satisfação média nos 3 blocos de perguntas que compunham o questionário: Estrutura de Trabalho, Bem-Estar Profissional e Qualidade de Ensino. Pode-se notar que o único bloco com insatisfações marcantes é relacionado à Qualidade do Ensino. Mais precisamente, o Engajamento dos Alunos nas aulas, que recebeu nota 3,2 \pm 1 e o nível de Dedicação e Responsabilização dos alunos pelo próprio aprendizado, cuja nota foi $2,8 \pm 1$. Estes foram os tópicos que apresentaram maior insatisfação na relação dos docentes com o trabalho.

Figura 2 - Avaliação da satisfação dos docentes na síntese dos 3 blocos mensurados.

\section{Estrutura de Trabalho}

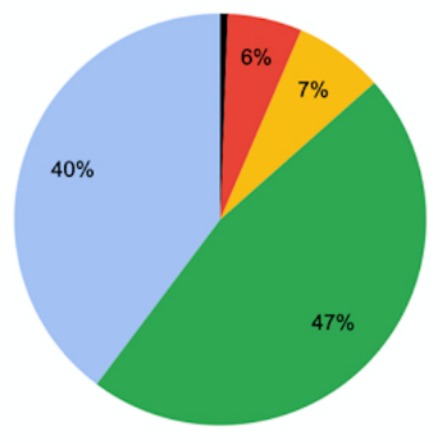

Bem-Estar Profissional

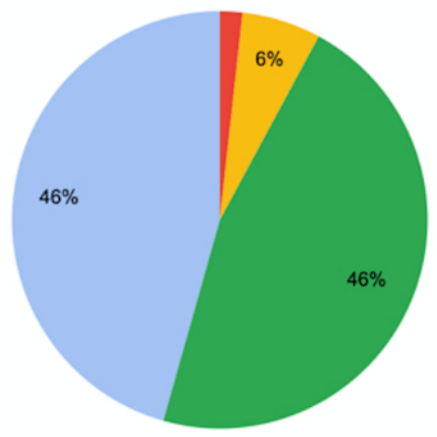

Qualidade do Ensino

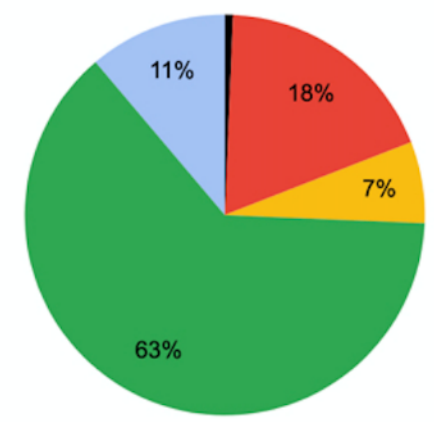

1 - Totalmente Insatisfeito

2 - Parcialmente Insatisfeito

3 - Indiferente

4 - Parcialmente Satisfeito

5 - Totalmente Satisfeito

Fonte: Questionário de Satisfação no Trabalho para docentes da engenharia de minas da UFMG (julho/2020)

Na perspectiva dos docentes, a cada semestre está mais difícil conquistar o foco dos alunos e muitos se sentem cada vez mais distantes da turma. A pesquisa indica que este é mais um efeito colateral da didática tradicional. A metodologia de aulas expositivas, ou como Vieira (p, 13, 2014) descreve, "aulas monológicas, com conteúdos expressos tais e quais nos livros didáticos", está se deteriorando e esgotando a si própria.

Segundo a Deloitte Global Millenial Survey (2019), 80\% dos jovens nascidos entre 1995 e 2010 considera trabalhar de forma independente em algum momento da vida ao invés de em uma organização tradicional. Uma metodologia pautada na centralização ao invés da 


\section{Evento On-line}

coparticipação, não está alinhada com a autonomia e pluralidade que caracteriza as gerações Nativas Digitais.

O futuro do ensino é uma incógnita, mas este estudo indica que um de seus componente principais é a evolução da experiência de ensino-aprendizagem de monólogos para diálogos. Quadros et al. (p. 646, 2017) descreve esse desafio como "superar a perspectiva de ensino limitada à transmissão de conteúdos e avançar na perspectiva de uma aula mais dialógica, que permita maior protagonismo dos estudantes no processo de aprendizagem".

É necessário adotar metodologias de ensino que permitam o amadurecimento dos discentes por meio do reconhecimento dos seus próprios interesses, curiosidades, incômodos, capacidades e cultura, e a exploração destes para direcionar parte do seu caminho singular de aprendizagem. A fim de deixar algum alimento para reflexão àqueles que desejam realizar essa transição de metodologias de ensino destaca-se a provocação de Allan Kaplan, em seu livro Artistas do Invisível:

"Nós aprendemos a reduzir; podemos aprender a expandir? Nós aprendemos a controlar; podemos aprender a respeitar? Nós aprendemos a medir, mas não aprendemos inteiramente a apreciar. Nós aprendemos a planejar e prever; mas sabemos como possibilitar e permitir?" (KAPLAN, p. 28, 2005)

\section{CONSIDERAÇÕES FINAIS}

A partir dessa investigação fica explícito que a satisfação acadêmica é um indicador que deve ser mantido em permanente monitoramento e debate. Pois, além de indicar pontos importantes para serem revistos ou melhorados no curso, mensura o desempenho dos serviços da Instituição e está intimamente relacionada ao sucesso profissional dos docentes e egressos.

Comprovou-se também, que existe uma transição na experiência de ensinoaprendizagem tomando forma. Ela pode ser entendida, em síntese, como a passagem das aulas como monólogos, para aulas como diálogos. A transição para uma cultura de diálogos é incerta, caótica e imprevisível, pois esta é a natureza do próprio diálogo em si. Entretanto, é uma jornada que promete recompensar com altas doses de engajamento, motivação, criatividade, colaboração e a formação de uma nova ordem de conhecimentos.

\section{Agradecimentos}

$\mathrm{O}$ autor agradece o apoio à coordenadora e professora Andreia Bicalho Henriques na aplicação dos questionários, ao Departamento de Engenharia de Minas, ao Colegiado e aos Discentes do Curso de Engenharia de Minas da Universidade Federal de Minas Gerais, por apoiarem e estimularem o desenvolvimento acadêmico.

\section{REFERÊNCIAS}

AUGUSTO, C. A., TAKAHASHI, L. Y., \& SACHUK, M. I.. Impacto da Inovação Tecnológica na Competitividade e nas Relações de Trabalho. Caderno De Administração, 16(2), 57-66, 2008.

ANGHINONI, Felipe. Contexto Mundial Educação. Perestroika. Metodologia Open Source da Experience Learning. Disponível em: https://experiencelearning.s3.amazonaws.com/pdfs/Br/8_Contexto_Mundial.pdf. Acesso em: 17 jun. 2015. ( 


\section{Evento On-line}

BAKHSHI, H., DOWNING, J., OSBORNE, M. The Future of Skills: Employment in 2030. Londres: Oxford Martin School, Pearson and Nesta. 2017.

BICALHO, H. Andreia, Citação de documento eletrônico. Disponível em: http://www.demin.ufmg.br/grad.php

BROWN, Juanita; ISAAC, Davids. O World Café: Dando Forma ao nosso Futuro por meio de Conversações Significativas e Estratégicas. São Paulo: Editora Cultrix. 2007.

DELOITTE, Global Millennial Research. Societal Discord and Technological Transformation Create a "Generation Disrupted". Disponível em: https://www2.deloitte.com/content/dam/Deloitte/global/Documents/About-Deloitte/deloitte2019-millennial-survey.pdf. Acesso em: 7 jul. 2019.

GOMES, G.; DAGOSTINI, L. CUNHA, P. R. Satisfação dos estudantes do curso de Ciências Contábeis: estudo em uma faculdade do Paraná. ReFAE, v. 4, n. 2, p. 102-123, 2013.

HAZOFF JUNIOR, Waldemar; SAUAIA, Antonio Carlos Aidar. Aprendizagem centrada no participante ou no professor? Um estudo comparativo em Administração de Materiais. Rev. adm. contemp., Curitiba, v. 12, n. 3, p. 631-658, Sept. 2008.

KAPLAN, Allan. O Processo Social e o Profissional de Desenvolvimento. Artistas do Invisível. Tradução de Ana Paula Pacheco. São Paulo: Instituto Fonte. Editora: Fundação Peirópolis. 2005.

SAWYER, R. Keith. Group Genius: O Poder Criativo da Colaboração. Nova York: Editora Basic Books, 2007.

SCHLEICH, A. L. R. POLYDORO, S. A. J. SANTOS, A. A. A. Escala de satisfação com a experiência acadêmica de estudantes de ensino superior. Avaliação Psicológica, v. 5, n. 1, 2006.

MATURANA, Humberto; VERDEN- ZÖLLER, Gerda; The Origin of Humanness in the Biology of Love. Reino Unido: Editora Imprit Academic. 2008.

NEGRI, Fernanda de; SQUEFF, Flávia. Sistemas Setoriais de Inovação e Estrutura de Pesquisa no Brasil. Brasília, IPEA : FINEP : CNPq. p. 15 - 18. 2016.

PALACIO, A. B.; MENESES, G. D.; PÉREZ, P. J. P. The configuration of the university image and its relationship with the satisfaction of students. Journal of Educational Administration, v. 40, n. 5, p. 486-505, 2002. 


\section{Evento On-line}

PINTO, N. G. M.; QUADROS, M. R. C.; CRUZ, F. V.; CONRAD, C. C. Satisfação acadêmica no ensino superior brasileiro: uma análise das evidências empíricas. Revista Brasileira de Ensino Superior, Passo Fundo, v. 3, n. 2, p. 3-17, dez. 2017.

PIRES, Camila. Mundo VUCA: O que é e como se preparar. Disponível em:https://redeindigo.com.br/mundo-vuca

preparar/\#: : :text=VUCA $\% 20 \% \mathrm{C} 3 \% \mathrm{~A} 9 \% 20 \mathrm{um} \% 20 \mathrm{acr} \% \mathrm{C} 3 \% \mathrm{~B} 4$ nimo $\% 20$ para, de $\% 2090 \% 20$ no\%20ambiente\%20militar. Acesso em: 20 jul. 2018.

QUADROS, A. et al. As aulas de graduação em uma universidade pública federal: planejamento, estratégias didáticas e engajamento dos estudantes. Rev. Bras. Educ., Rio de Janeiro, v. 22, n. 70, p. 625-650. Disponível em:

http://www.scielo.br/scielo.php?script=sci arttext\&pid=S1413-

$24782017000300625 \& \operatorname{lng}=\mathrm{en} \& \mathrm{nrm}=\mathrm{iso}$. Acesso em 12 jul. 2017.

STICKDORN, Marc; SCHNEIDER, Jakob. Isto é Design Thinking de Serviços. Amsterdam: Editora BIS Publisher. 2010.

VIDOTTO, Luiz; SILVA, Dirceu; LABURÚ, Carlos. Avaliação Tradicional e Alternativa no Ensino: um Estudo Comparativo. Londrina, v. 26, p. 27-42, set. 2005.

WARREN, Bennis; BIEDERMAN, Patricia. Organizing Genuis: The Secrets of Creative Collaboration. California: Editora Perseus Books. 1997.

\section{ENGINEERING EDUCATION FROM THE PERSPECTIVE OF STUDENTS AND TEACHERS: A CASE STUDY OF MINING ENGINEERING FROM THE FEDERAL UNIVERSITY OF MINAS GERAIS}

Abstract: This work presents an analysis from the perspective of the professors and students of the UFMG School of Mining Engineering in relation to the course and the institution. Through an exploratory survey, parameters related to satisfaction regarding the quality of teaching, school infrastructure and connection with the market were quantified and qualified. The analysis and debate of the results allows us to infer the main weaknesses and qualities of the course, as well as the next steps that can lead the institution to renew its teaching and learning process. The due projections of this work can be used to optimize the teaching methodologies of the various Higher Education Institutions.

Keywords: Academic Satisfaction. Innovation. Teaching Methodologies. Engineering. 